ASIMTOT: JURNAL KEPENDIDIKAN MATEMATIKA

Volume 3 Nomor 2, Juni - November 2021, halaman 151 - 156

Tersedia Daring pada https://journal.unwira.ac.id/index.php/ASIMTOT

\title{
PENGGUNAAN ALAT PERAGA DALAM UPAYA MENINGKATAN HASIL BELAJAR MATEMATIKA POKOK BAHASAN DIMENSI TIGA
}

\section{THE USE OF PROPS IN THE EFFORT TO INCREASE THE THREE DIMENSIONAL MATHEMATICS LEARNING}

\author{
Margareta Gena \\ SMAK Giovanni Kupang \\ Email: genadjong@gmail.com
}

\begin{abstract}
Abstrak: Penelitian ini bertujuan untuk mengetahui adanya peningkatan hasil belajar dimensi tiga pada siswa kelas XII yang diajar dengan menggunakan alat peraga. Jenis penelitian yang dilakukan adalah penelitian tindakan kelas yang terdiri dari dua siklus. Penelitian ini mengacu pada model Kemmis dan Mc Taggart yang setiap siklusnya terdiri dari empat tahap yakni perencanaan, pelaksanaan tindakan, observasi dan refleksi. Subyek dari penelitian ini terdiri dari 30 siswa kelas XII SMAK Giovanni. Instrumen yang digunakan adalah tes dan lembar pengamatan guru dan siswa. Hasil penelitian menunjukkan bahwa penggunaan alat peraga dapat meningkatkan rata-rata hasil belajar siswa dari 75 pada siklus 1 menjadi 87,5 pada siklus 2 . Peningkatan ini juga terjadi pada aktivitas siswa dengan capaian indikator $62,5 \%$ pada siklus 1 menjadi $85,42 \%$ pada silus 2 . Skor kemampuan guru dalam mengelola pembelajaran juga meningkat dari 2,95 (cukup) pada siklus 1 menjadi 3,75 (baik) pada siklus 2. Ketuntasan klasilkal juga meningkat dari 73,33\% pada siklus 1 menjadi $100 \%$ pada siklus 2. Dengan menggunakan alat peraga, siswa lebih antusias dalam mengikuti pembelajaran di sekolah.
\end{abstract}

Kata Kunci: alat peraga, dimensi tiga, hasil belajar

Abstract: This study aims to determine the increase in three-dimensional learning outcomes in class XII students who are taught using visual aids. The type of research conducted is classroom action research which consists of two cycles. This study refers to the model of Kemmis and Mc Taggart which each cycle consists of four stages, namely planning, implementing actions, observing and reflecting. The subjects of this study consisted of 30 class XII students of SMAK Giovanni. The instruments used were tests and observation sheets for teachers and students. The results showed that the use of teaching aids could increase the average student learning outcomes from 75 in cycle 1 to 87.5 in cycle 2. This increase also occurred in student activities with indicator achievement of $62.5 \%$ in cycle 1 to $85.42 \%$. in cycle 2. The teacher's ability score in managing learning also increased from 2.95 (enough) in cycle 1 to 3.75 (good) in cycle 2. Classical completeness also increased from $73.33 \%$ in cycle 1 to $100 \%$ in cycle 2. By using teaching aids, students are more enthusiastic in participating in learning at school.

Keywords: teaching aids, three dimensions, learning outcomes

Cara Sitasi: Gena, M. (2021). Penggunaan Alat Peraga Dalam Upaya Meningkatkan Hasil Belajar Matematika Pokok Bahasan Dimensi Tiga. Asimtot: Jurnal Kependidikan Matematika, “3”(“2”), “147-” 
SSIM!OI',

Pendidikan merupakan sesuatu yang penting dalam mencerdaskan kehidupan suatu bangsa dan diperlukan guna meningkatkan mutu bangsa secara menyeluruh. Menurut Anisah (217), pendidikan adalah usaha sadar dan terencana untuk mewujudkan suasana belajar dan proses pembelajaran agar peserta didik secara aktif mengembangkan potensi dirinya untuk memiliki kekuatan spiritual keagamaan, pengendalian diri, kepribadian, kecerdasan, akhlak mulia, serta keterampilan yang diperlukan dirinya, masyarakat, bangsa dan negara. Peningkatan mutu pendidikan ditentukan oleh kesiapan sumber daya manusia yang terlibat dalam proses pendidikan.

Guru sebagai ujung tombak pendidikan merupakan salah satu faktor penentu tinggi rendahnya hasil pendidikan mempunyai posisi strategi, maka setiap usaha peningkatan mutu pendidikan perlu memberikan perhatian besar kepada peningkatan guru baik dalam segi jumlah maupun mutunya (Marianita dan Yuneti, 2019). Untuk itu dalam menunjang kegiatan guru, diperlukan iklim sekolah yang kondusif dan hubungan yang baik antar unsur-unsur yang ada di sekolah antara lain kepala sekolah, guru, tenaga administrasi dan peserta didik. Serta hubungan baik antar unsur-unsur yang ada di sekolah dengan orang tua murid maupun masyarakat.

Alat peraga adalah alat yang dapat membantu peserta didik untuk lebih memahami konsep (KKBI,2007). Menurut Estiningsih (Nasaruddin, 2015) alat peraga merupakan media pembelajaran yang mengandung atau membawakan ciri-ciri dari konsep yang dipelajari. Alat peraga sebagai demonstrasi kit mencirikan konsep materi pembelajaran yang digunakan untuk mendemonstrasikan topik, sehingga topik dapat dengan mudah dipahami oleh siswa. Dengan demikian, alat peraga adalah bagian dari bahan ajar atau alat yang dapat digunakan guru dalam mengajarkan konsep atau rumus kepada siswanya, sehingga dapat menjadi mudah dipahami. Alat peraga sangat bermanfaat bagi guru dalam proses pembelajaran.

Sukayati (2009) berpendapat bahwa segala sesuatu yang digunakan dalam pembelajaran matematika dapat digolongkan sebagai alat peraga matematika. Alat peraga matematika adalah alat yang dibuat oleh pabrik, guru, atau benda dan digunakan oleh guru dan siswa dalam pembelajaran matematika. Menurut Briggs harus ada sesuatu untuk mengkomunikasikan materi (pesan kurikuler) supaya terjadi proses belajar. Karena itu dia mendefinisikan alat peraga sebagai wahana fisik yang mengandung materi pembelajaran (Nasution, 2004).

Alat peraga dalam pembelajaran juga bermanfaat bagi siswa. Alat peraga ini dapat: (1) membantu dalam meningkatkan pengetahuan dan keterampilan, (2) mengilustrasikan dan meningkatkan pesan atau informasi, dan (3) menghilangkan kendala, dan kemalasan (Abbas \& Zakaria, 2018). Dengan demikian, alat peraga dapat digunakan oleh guru dan siswa dalam pembelajaran termasuk dalam proses pembelajaran matematika. 


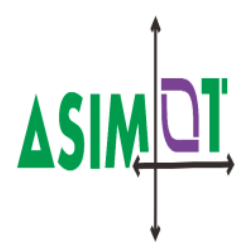

Geometri adalah salah satu bagian dalam mata pelajaran matematika yang diajarkan di sekolah menengah atas (SMA). Salah satu materi Geometri yang diajarkan di SMA adalah tentang dimensi tiga yang meliputi jarak titik ke garis, jarak titik ke bidang, jarak garis ke garis dan jarak garis ke bidang. Konsep ini perlu dikuasai siswa agar mampu menggunakan dalam memecahkan masalah matematika dan masalah lain dalam kehidupan sehari-hari. Penguasaan konsep geometri oleh siswa SMA dapat diajarkan dengan menggunakan alat peraga. Alat peraga menjadi salah satu solusi untuk mengatasi kesulitan siswa dalam memecahkan masalah. Terutama pada materi pokok dimensi tiga. Untuk mempelajari materi pokok dimensi tiga diperlukan kemampuan penalaran matematika yang bagus, memahami konsep materi dan harus bisa memvisualisasikan bangun ruang.

Menurut Novita dkk (2018) beberapa penyebab kesulitan dalam mempelajari dimensi tiga antara lain adalah: 1 . Penjelasan guru yang sulit untuk dipahami oleh siswa (padahal sudah diperhatikan dengan baik), sehingga mereka kesulitan untuk mengikuti materi ini (sulit mengikuti ketika guru menjelaskan; guru terlalu cepat menjelaskan; guru kurang bisa menjelaskan kepada siswa; guru menjelaskan tidak terstruktur). 2. Kurangnya penggunaan media konkrit seperti alat peraga oleh guru sehingga hal yang bersifat abstrak susah dibayangkan oleh responden (kesulitan dalam melukis bangunbangun ruang, kesulitan membayangkan bendabenda/unsur-unsur yang tidak nampak, siswa dituntut mengkhayal). 3. Kurangnya aktivitas pembelajaran yang bermakna sehingga pembelajaran hanya terkesan pada penguasaan sejumlah teori (kesulitan menghafal rumus, kesulitan dalam memahami dan menyelesaikan soal-soal yang terkait dengan dimensi tiga).

Berdasarkan apa yang disampaikan pada bagian pendahuluan, penulis tertarik untuk mengadakan penelitian tindakan kelas dengan judul Penggunaan Alat Peraga Dalam Upaya Peningkatan Prestasi Belajar Matematika Pokok Bahasan Dimensi Tiga Pada Siswa Kelas XII IPS 5 SMA Katolik Giovanni Kupang.

\section{Metode Penelitian}

Jenis penelitian yang digunakan adalah penelitian tindakan kelas. Pelaksanaan penelitian tindakan kelas ini dilakukan melalui 2 (dua) siklus, dimana pada masingmasing siklus terdiri dari 4 tahap yakni: perencanaan, pelaksanaan tindakan, observasi dan refleksi.

Subyek dari penelitian ini adalah seluruh siswa kelas XII IPS 5 SMAK Giovanni Kupang yang berjumlah 30 siswa. Instrumen yang digunakan dalam peneltian ini adalah tes hasil belajar, lembar pengamatan kemampuan guru mengelola pembelajaran dan lembar aktivitas siswa. Data yang terkumpul akan dianalisis dengan menggunakan statistik deskriptif. 
SSIM!|i'

Hasil Penelitian dan Pembahasan

\section{Hasil}

Sebelum kegiatan pembelajaran dilakukan, peneliti menyiapkan sejumlah perangkat yang dibutuhkan antara lain RPP, soal tes, lembar pengamatan guru dan siswa serta media pembelajaran dalam hal ini alat peraga yang berupa kerangka kubus dan balok serta benang tebal berwarna-warni. Selain itu peneliti juga mengundang dua rekan guru sebagai pengamat yang akan mengamati proses pembelajaran yang dilakukan oleh peneliti maupun keaktifan siswa dalam kegiatan pembelajaran.

1. Hasil penelitian pada siklus 1

a) Hasil belajar pada siklus 1 disajikan pada tabel 1 di bawah ini:

Tabel 1. Hasil Belajar Siswa Pada Siklus I

\begin{tabular}{lcc}
\hline Hasil Belajar & $\begin{array}{c}\text { Tes } \\
\text { Awal }\end{array}$ & $\begin{array}{c}\text { Tes Akhir } \\
\text { Siklus 1 }\end{array}$ \\
\hline Nilai Minimum & 20 & 65 \\
\hline Nilai Maksimum & 70 & 80 \\
\hline Rata-Rata & 40,13 & 75 \\
\hline $\begin{array}{l}\text { Jumlah Ketuntasan } \\
\text { Individu }\end{array}$ & 0 & 22 \\
\hline $\begin{array}{l}\text { Ketuntasan Klasikal } \\
(\%)\end{array}$ & 0 & 73,33 \\
\hline
\end{tabular}

b) Hasil lembar observasi kemampuan guru dalam mengelola pembelajaran pada siklus 1 menunjukkan perolehan skor rata-rata 2,95 dengan kriteria cukup.

c) Hasi lembar observasi aktivitas siswa pada siklus 1 mencapai rata-rata skor 15 dengan capaian indikator $62,5 \%$ dengan kriteria baik

2. Hasil penelitian pada siklus 2

a) Hasil belajar siswa pada siklus 2 disajikan pada tabel 2 di bawah ini:

Tabel 2. Hasil belajar siswa pada siklus 2

\begin{tabular}{lcc}
\hline Hasil Belajar & $\begin{array}{c}\text { Tes } \\
\text { Awal } \\
\text { Siklus 1 }\end{array}$ & $\begin{array}{c}\text { Tes Akhir } \\
\text { Siklus 2 }\end{array}$ \\
\hline Nilai Minimum & 20 & 65 \\
\hline Nilai Maksimum & 70 & 80 \\
\hline Rata-Rata & 40,13 & 75 \\
\hline $\begin{array}{l}\text { Jumlah Ketuntasan } \\
\text { Individu }\end{array}$ & 0 & 22 \\
\hline $\begin{array}{l}\text { Ketuntasan Klasikal } \\
(\%)\end{array}$ & 0 & 73,33 \\
\hline
\end{tabular}

b) Hasil lembar observasi kemampuan guru dalam mengelola pembelajaran pada siklus 2 menunjukkan perolehan skor rata-rata 3,75 dengan kriteria baik.

c) Hasi lembar observasi aktivitas siswa pada siklus 2 mencapai rata-rata skor 20,5 dengan capaian indikator $85,42 \%$ dengan kriteria sangat baik.

\section{Pembahasan}

Pembahasan difokuskan pada mengaitkan data dan hasil analisisnya dengan permasalahan atau tujuan penelitian dan konteks teoretis yang lebih luas. Dapat juga pembahasan merupakan jawaban pertanyaan mengapa ditemukan fakta seperti pada data?

Berdasarkan tabel 1 dan 2, hasil belajar siswa pada siklus 1 dan siklus 2 dapat digambarkan pada gambar 1 di bawah ini. 
ASIMTOT: JURNAL KEPENDIDIKAN MATEMATIKA

Volume 3 Nomor 2, Juni - November 2021, halaman 151 - 156

Tersedia Daring pada https://journal.unwira.ac.id/index.php/ASIMTOT

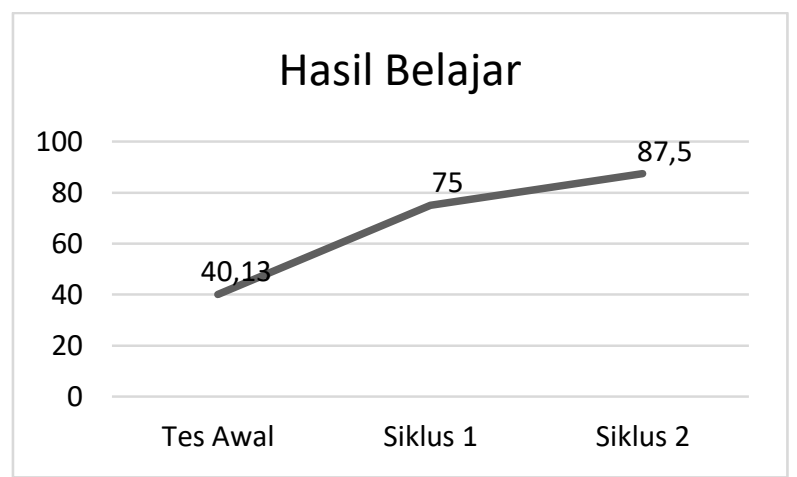

Gambar 1. Hasil Belajar siswa

Berdasarkan gambar 1 ini terlihat bahwa ada peningkatan rata-rata hasil belajar dari 75 pada siklus 1 dengan ketuntasan klasikal 77,33\% (22 siswa)menjadi rata-rata hasil belajar 87,5 dengan ketuntasan klasikal $100 \%$ (30 siswa) pada siklus 2. Hal ini disebabkan siswa termotivasi menggunakan alat peraga untuk memahami persoalan yang diberikan sebagaimana pendapat Heinich (Hartoyo, 2006) yang mengatakan bahwa alat peraga memberi kesempatan kepada siswa untuk belajar dari tangan pertama, untu menyentuh, mengamati, bereksperimen, bertanya dan menentukan.

Hasil lembar pengamatan kemampuan guru dalam mengelola pembelajaran dapat dilihat pada gambar 2 di bawah ini:

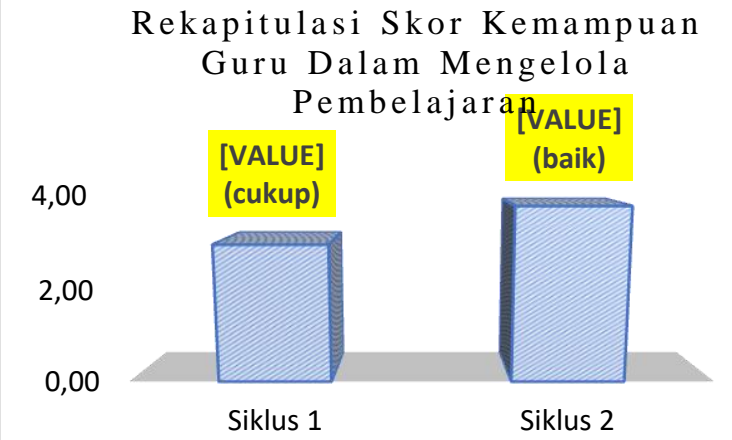

\section{Gambar 2. Skor Hasil Observasi Kemampuan Guru}

Dari gambar 2 ini terlihat bahwa ada peningkatan kemampuan guru dalam mengelola pembelajaran. Pada siklus 1 ratarata skor kemampuan guru mengelola pembelajaran 2,95 dalam kategori cukup dan pada siklus 2 meningkat menjadi 3,75 dalam kategori baik. Hal ini bisa dikatakan guru mulai terbiasa mengelola pembelajaran yang menggunakan alat peraga dalam mengajar materi dimensi tiga.

Hasil lembar pengamatan aktivitas siswa dapat dilihat dalam gambar 3 di bawah ini:

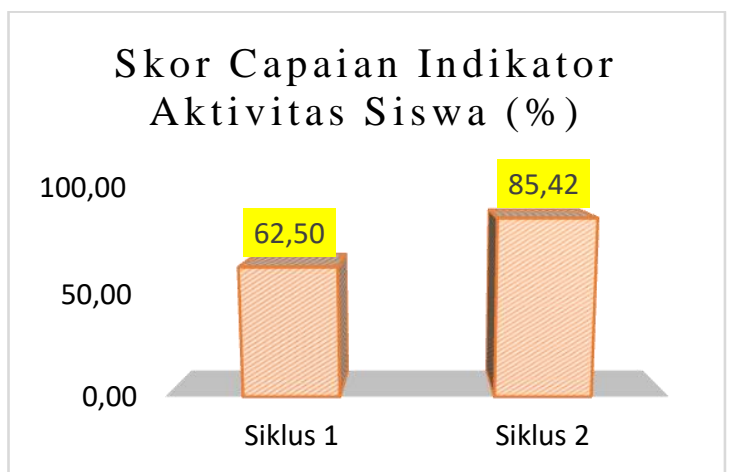

\section{Gambar 3. Skor Capaian Indikator Aktivitas Siswa}

Dari gambar 3 ini juga terlihat ada peningkatan aktivitas siswa dari capaian indikator $62,5 \%$ pada siklus 1 menjadi 


\section{ASIMTOT: JURNAL KEPENDIDIKAN MATEMATIKA}

Volume 3 Nomor 2, Juni - November 2021, halaman 151 - 156

Tersedia Daring pada https://journal.unwira.ac.id/index.php/ASIMTOT

$85,42 \%$ pada siklus 3 . Hal ini menunjukkan bahwa siswa mulai aktif dan bersemangat emnggunakan alat peraga dalam melaksanakan pembelajaran. Peningkatan keaktifan siswa ini juga dipengaruhi oleh peningkatan kemampuan guru dalam mengelola pembelajaran terutama dalam memotivasi dan membimbing siswa.

\section{Simpulan dan Saran}

\section{Simpulan}

Berdasarkan hasil penelitian dan pembahasan maka dapat disimpulkan: (1) Penggunaan alat peraga dapat meningkatkan rata-rata hasil belajar siswa dari 75 menjadi 87,5 dan ketuntasan klasikal dari 73,33\% menjadi 100\%, (2) Penggunaan alat peraga juga meningkatkan skor kemampuan guru mengelola pembelajaran dari 2,95 dalam kategori cukup menjadi 3,75 dalam kategori baik.

\section{Saran}

Dari hasil penelitian ini disarankan kepada guru dalam melaksanakan pembelajaran geometri khususnya matei dimensi tiga agar dapat menggunakan alat peraga sederhana yang dapat digunakan dalam mendukung pemahaman siswa dalam proses pembelajaran.

\section{Daftar Pustaka}

Depdiknas. (2007). Kamus Besar Bahasa Indonesia, Edisi Ketiga. Jakarta: Balai Pustaka.

Nasaruddin, N. (2015). Media Dan Alat Peraga Dalam Pembelajaran Matematika. Al-Khwarizmi:

Jurnal Pendidikan Matematika dan Ilmu Pengetahuan Alam, 3(2), 21-30.

S. Sukayati. (2009). Pemanfaatan Alat Peraga Matematika dalam Pembelajaran di Sekolah Dasar. Yogyakarta: PPPPTK Matematika

Nasution, N. (2004). Psikologi belajar. Jakarta: Gramedia Pustaka Utama.

Novita, R., Prahmana, R. C. I., Fajri, N., \& Putra, M. (2018). Penyebab kesulitan belajar geometri dimensi tiga. Jurnal Riset Pendidikan Matematika, 5(1), 18-29.

Abbas, N., \& Zakaria, P. (2018, June). The implementation of mathematics props-based learning on geometry concept. In Journal of Physics: Conference Series (Vol. 1028, No. 1, p. 012157). IOP Publishing.

Sulastri, E., Hartono, Y., \& Puri, R. I. I. (2010). Upaya Meningkatkan Hasil Belajar Siswa Pada Pokokbahasan Dimensi Tiga Melalui Model Pembelajaran Learning Cycle Di Kelas Xi Tkj 1 SMKN 2 Palembang. Jurnal 
ASIMTOT: JURNAL KEPENDIDIKAN MATEMATIKA

Volume 3 Nomor 2, Juni - November 2021, halaman 151 - 156

Tersedia Daring pada https://journal.unwira.ac.id/index.php/ASIMTOT

Pendidikan Matematika, 4(1), 1124.

Rosminah, R. (2018). Upaya Menanggulangi Kesulitan Siswa Mempelajari Pokok Bahasan Dimensi Tiga Dengan Menggunakan Metode Penemuan Terbimbing Yang Disertai Alat Peraga Di Kelas X S Negeri 1 Tanjung Balai Tahun Ajaran 2014/2015. Jurnal Edukasi Kultura: Jurnal Bahasa, Sastra dan Budaya, 5(2). 